\title{
Aortic prosthetic size predictor in aortic valve replacement
}

\author{
Anh Tuan Vo ${ }^{1} \mathbb{D}$, Tomomi Nakajima², Trang Thi Thu Nguyen' ${ }^{1}$, Nguyen Thoi Hai Nguyen ${ }^{3}$, Nga Bich Le ${ }^{3}$, \\ Tri Huu Cao ${ }^{4}$ and Dinh Hoang Nguyen ${ }^{1,3^{*}}$
}

\begin{abstract}
Background: Patient-prosthesis mismatch (PPM) is a major concern in aortic valve replacement (AVR) and leads to perioperative morbidity and rehospitalization. Predicting aortic annulus diameter pre-procedurally is crucial to managing patients with high-risk of PPM.
\end{abstract}

Objectives: To compare preoperative measurements of aortic annulus from echocardiography and CT scan with surgical sizing and develop an imaging-based algorithm to predict PPM.

Methods: From January 2017 to December 2020, patients underwent AVR at a teaching hospital were examined. The relationship between imaging measurements with operative values was assesed using scatter plots and Pearson's correlation coefficient. Univariable linear regression was then used to build the predictive model.

Results: A total of 144 patients underwent AVR during the study period. Suture types and surgical approaches were not significantly associated with prosthesis size. CT scan-based measurements showed strong correlation with prosthesis size: mean diameter $(R=0.79)$, perimeter-derived diameter $(R=0.76)$, and area-derived diameter $(R=0.75)$. Mechanical valve and tissue valve shared similar correlation coefficients. Prosthesis size predictive models based on CT scan were $12.89+0.335 \times \mathrm{d}$ for mean diameter, $13.275+0.315 \times \mathrm{d}$ for perimeter-derived diameter and $13.626+0.309 \times d$ for area-derived diameter.

Conclusions: Preoperative CT scan measurements are a reliable predictor of aortic prosthesis size. Transthoracic echocardiography is a possible alternative, though it is highly performer-dependent and unable to represent the aortic annulus fully. Together, these two imaging modalities can be used to quantitatively anticipate PPM preoperatively.

Keywords: Prosthetic size predictor, Patient-prothesis mismatch, Computed tomography, Transthoracic echocardiography

\section{Introduction}

Aortic valve replacement (AVR) remains the gold standard for patients with valvular lesions like aortic stenosis. A major complication following AVR is patient-prosthesis mismatch (PPM), a nonstructural dysfunction. First described in 1978 [1], PPM occurs when excessive

\footnotetext{
*Correspondence: Dinh.nh@umc.edu.vn

${ }^{1}$ Department of Cardiovascular Surgery, University Medical Center,

University of Medicine and Pharmacy at Ho Chi Minh City, 215 Hong Bang Street, District 5, Ho Chi Minh City, Vietnam

Full list of author information is available at the end of the article
}

pressure gradient is generated across a normally functioning prosthetic valve. Its severity is determined by the indexed effective orifice area (EOAi) as follows: not clinically significant (none or mild) when $>0.85 \mathrm{~cm}^{2} / \mathrm{m}^{2}$, moderate when between 0.65 and $0.85 \mathrm{~cm}^{2} / \mathrm{m}^{2}$, and severe when $\leq 0.65 \mathrm{~cm}^{2} / \mathrm{m}^{2}$.

While the negative impact of PPM in the early recovery period is controversial, it generally increases perioperative morbidity and rehospitalization due to heart failure and lack of left ventricular mass regression, and eventually long-term mortality $[2,3]$. Several factors were found original author(s) and the source, provide a link to the Creative Commons licence, and indicate if changes were made. The images or other third party material in this article are included in the article's Creative Commons licence, unless indicated otherwise in a credit line to the material. If material is not included in the article's Creative Commons licence and your intended use is not permitted by statutory regulation or exceeds the permitted use, you will need to obtain permission directly from the copyright holder. To view a copy of this licence, visit http://creativecommons.org/licenses/by/4.0/. The Creative Commons Public Domain Dedication waiver (http://creativeco mmons.org/publicdomain/zero/1.0/) applies to the data made available in this article, unless otherwise stated in a credit line to the data. 
to increase the likelihood of PPM, including female sex, younger age, high body surface area (BSA), left ventricular end systolic diameter, aortic root dimension [4], hypertension, diabetes, renal failure, and utilization of bioprothesis [5]. Among these, calculating BSA from a patient's height and weight has been suggested as the first in a simple three-step algorithm to determine the type and size of prosthesis according to EOAi's reference values [6]. The aforementioned risk factors can easily be recognized clinically and preoperatively; however, their qualitative nature prevents surgeons from knowing whether further operative considerations, such as aortic root enlargement (ARE), are warranted.

With the above limitations in mind, multimodality imaging has been proposed as a powerful and comprehensive approach to identify and quantitate PPM [7]. 2D/3D transthoracic (TTE) and multidetector computed tomography $(\mathrm{CT})$ remain the most widely used tools to measure the aortic annulus dimensions pre-procedurally [3]. Previous studies have documented the superiority of CT measurements as compared to echocardiographic values and recommended the former to be routinely included in prosthesis sizing [8]. In practice, however, some inconsistencies still exist between calculated values and actual manufacturers' prothesis size. Hence, a more direct and robust imaging-based algorithm would significantly improve the ability to predict PPM before implantation.

Herein, we examined AVR cases from our institution and assessed the correlation between the aortic valve diameter as measured by echocardiography and CT scan preoperatively versus the true size of implanted valve. Our aim is to develop an imaging-based algorithm to predict the prosthesis valve size prior to AVR.

\section{Methods}

\section{Study design}

This retrospective cohort study included patients who underwent AVR at the Department of Cardiovascular Surgery, University Medical Center at Ho Chi Minh City from January 2017 to December 2020. All patients had 128-slice CT scan and TTE and both were used to calculate the aortic annulus.

The aortic annulus is a crown-shaped structure that serves as the insertion point for the aortic cusps. Its highest and lowest points are located at each of the three commissures and between any two of them, respectively. The annulus, which lacks a planar structure, is compressed to the round-shaped prosthesis after conventional AVR. We therefore assumed that prothesis size is correlated with the plane passing all three nadirs of the aortic valve.

Using TTE, the diameters of aortic annulus and left ventricular outflow tract (LVOT), as well as the sinus of Valsalva, sinotubular junction (STJ) and ascending aorta, were measured on the parasternal long axis view (PLAX) (Fig. 1). While reproducible, the results were greatly dependent on echocardiographers.

On CT scan, we employed multiplanar reconstruction $\left(\right.$ OsiriX ${ }^{\mathrm{TM}}$ software, Bernex, Switzerland) to map out the plane that passes through three nadirs of the aortic valve. The largest, smallest, average, perimeterderived and area-derived diameters were then calculated (Fig. 2).

All diameters were measured at end-systole.

\section{Surgical techniques}

We performed AVR via three approaches: conventional full sternotomy, upper ministernotomy or second intercostal minithoracotomy. For the minimally invasive procedures, peripheral cardiopulmonary bypass $(\mathrm{CPB})$ was established with femoral vessels. Custodiol ${ }^{\circledR}$ HTK Solution was delivered antegradely into the aortic root or the coronary ostia in patients with severe aortic regurgitation and was repeated every $120 \mathrm{~min}$ if necessary. We used single annular sutures for intra-annular valve replacement and ventricular-side pledgeted sutures for supra-annular valve replacement. Pledgeted sutures (supra-annular fashion) were utilized when severe calcifications were found on the valve leaflets and annulus. Finally, transesophageal echocardiography (TEE) was used to assess the surgery results.

For mechanical valve, we used SJM ${ }^{\mathrm{TM}}$ Masters Series Mechanical Heart Valve (Abbott Laboratories, Chicago, Illinois, USA). For tissue valve, we used CarpentierEdwards PERIMOUNT Magna Ease (Edwards Lifesciences, Irvine, California, USA).

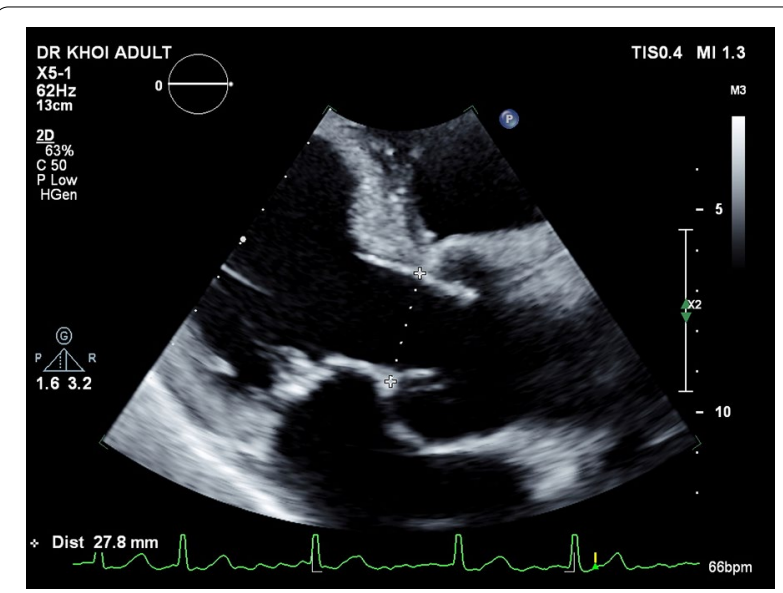

Fig. 1 Measurement of aortic annulus diameters on TTE 

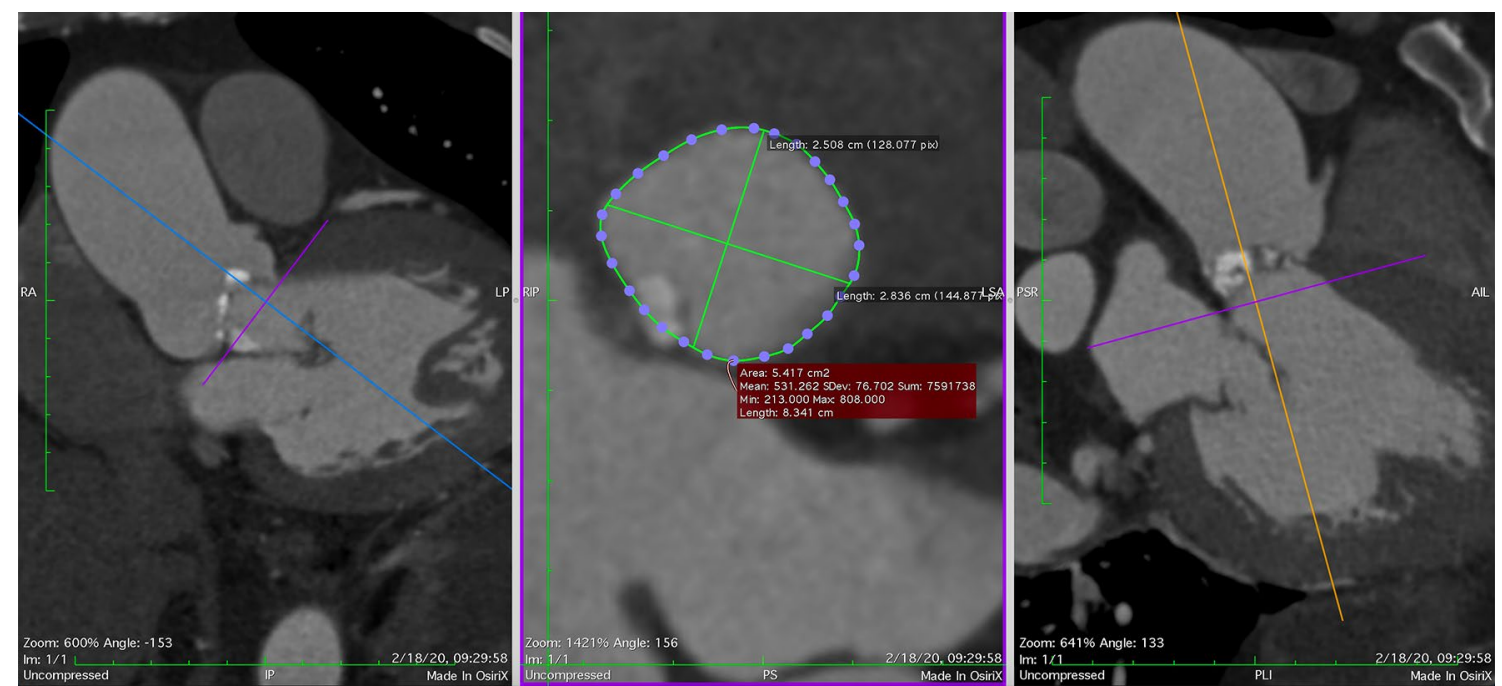

Fig. 2 Measurement of aortic annulus diameters on CT scan

\section{Statistical analysis}

Data analysis was performed using MedCalc version 19 (Medcalc Software Ltd, Ostend, Belgium). The associations between imaging measurements and valve size were evaluated using scatter plots and Pearson's correlation coefficients. Linear regression model was used to predict the surgical sizing from imaging-based values. As strong correlations between parameters were found, we performed univariable linear regression and selected the highest correlated measurements to build the prediction model (outcome $=\mathrm{a}+\mathrm{b} \times$ measurement; $\mathrm{a}$ : intercept; $\mathrm{b}$ : slope). The $95 \%$ confidence interval (CI) of the slope and intercept are reported. We analyzed the whole dataset and then performed subgroup analyses for tissue valve and mechanical valve. Statistically significant $p$ value was set to equal or less then 0.05 .

\section{Results}

A total of 144 patients were included in our study. Baseline and operative characteristics are presented in Tables 1 and 2, respectively. Overall, we found no significant differences in the durations of cardiopulmonary bypass, cross-clamp, mechanical ventilation and ICU stay among three surgical techniques. Interestingly, patients undergoing second intercostal minithoracotomy had longer $\mathrm{CPB}$ and cross-clamp time but shorter mechanical ventilation length and ICU stay. Regarding adverse outcome, one death occured at postoperative day five due to cerebral hemorrhage. No aortic dissection was recorded. Nine patients required reoperation due to bleeding, including five cases of full sternotomy, three upper ministernotomies
Table 1 Baseline characteristics

\begin{tabular}{ll}
\hline Variable & Cohort $(\mathbf{n}=\mathbf{1 4 4})$ \\
\hline Demographic variables & \\
Age (years) & $56.2 \pm 14.6$ \\
Sex (female) & $60(41.6)$ \\
Comorbidities, $\mathrm{n}(\%)$ & \\
Hypertension & $65(45.1)$ \\
Type Il diabetes mellitus & $31(21.5)$ \\
Preoperative atrial fibrillation & $49(34.0)$ \\
AVRvariables & \\
Etiology of aortic valve lesions, $\mathrm{n}(\%)$ & \\
Post rheumatic & $31(21.5)$ \\
Degenerative & $51(35.4)$ \\
Congenital & $62(43.1)$ \\
Approach & \\
Full sternotomy & $68(47.2)$ \\
Upper ministernotomy & $47(32.6)$ \\
Second intercostal minithoracotomy & $29(20.1)$ \\
Prosthesis type & \\
Mechanical valve & $62(43.1)$ \\
Tissue valve & $82(56.9)$ \\
Valve size (mm), mean \pm SD & $21.36 \pm 1.8$ \\
Mechanical valve & $21.2 \pm 1.77$ \\
Tissue valve & $21.5 \pm 1.74$ \\
\hline AVR aoricvave replacent &
\end{tabular}

AVR aortic valve replacement

and one second intercostal minithoracotomy. Operative approach was changed to full sternotomy in two patients due to uncontrolled bleeding (upper ministernotomy, one case) and poor exposure (second intercostal minithoracotomy, one case). 
Table 2 Intraoperative details

\begin{tabular}{|c|c|c|}
\hline Variable & & $P$ value \\
\hline \multicolumn{3}{|l|}{ Cardiopulmonary bypass time (minutes) } \\
\hline Total & $116.5 \pm 35.1$ & \\
\hline Full sternotomy & $104.5 \pm 36.0$ & 0.281 \\
\hline Upper ministernotomy & $108.5 \pm 21.7$ & \\
\hline Second intercostal minithoracotomy & $126.6 \pm 25.7$ & \\
\hline \multicolumn{3}{|l|}{ Cross-clamp time (minutes) } \\
\hline Total & $82.7 \pm 21.6$ & \\
\hline Full sternotomy & $69.6 \pm 20.2$ & 0.090 \\
\hline Upper ministernotomy & $66.5 \pm 16.1$ & \\
\hline Second intercostal minithoracotomy & $92.3 \pm 17.5$ & \\
\hline \multicolumn{3}{|l|}{ Mechanical ventilation time (hours) } \\
\hline Total & $36.2 \pm 28.6$ & \\
\hline Full sternotomy & $43.9 \pm 30.7$ & 0.112 \\
\hline Upper ministernotomy & $31.7 \pm 30$ & \\
\hline Second intercostal minithoracotomy & $23.5 \pm 8.9$ & \\
\hline \multicolumn{3}{|l|}{ Length of ICU stay (days) } \\
\hline Total & $3.3 \pm 1.4$ & \\
\hline Full sternotomy & $3.7 \pm 1.3$ & 0.49 \\
\hline Upper ministernotomy & $2.9 \pm 1.7$ & \\
\hline Second intercostal minithoracotomy & $2.9 \pm 1.3$ & \\
\hline \multicolumn{3}{|l|}{ Postoperative complications, n (\%) } \\
\hline Mortality & $1(0.69)$ & \\
\hline Permanent stroke & $2(1.4)$ & \\
\hline Aortic dissection & $0(0)$ & \\
\hline Prolonged mechanical ventilation* & $21(14.6)$ & \\
\hline Renal failure requiring dialysis & $6(4.2)$ & \\
\hline Reoperation for bleeding & $9(6.3)$ & \\
\hline Full sternotomy & 5 & \\
\hline Upper ministernotomy & 3 & \\
\hline Second intercostal minithoracotomy & 1 & \\
\hline Conversion to full sternotomy & 2 & \\
\hline Upper ministernotomy $(n=47)$ & $1(2.2)$ & \\
\hline Second intercostal minithoracotomy $(n=29)$ & $1(6.9)$ & \\
\hline
\end{tabular}

Table 3 illustrates prosthesis size as according to two suture techniques, namely intra-annular single suture and supra-annular pledgeted suture, and three surgical approaches. Neither parameters significantly affect the prosthesis size.

The relationship between diameters calculated by imaging modalities and the implanted prothesis size was computed using Pearson correlation coefficients (Table 4) and graphed as scatterplots (Fig. 3). TTE-measured diameters showed the weakest correlation, whereas those calculated from CT scan were strongly correlated with surgical prosthesis sizing (coefficients were greater than 0.70 for all diameters and for both mechanical and tissue valve). Hence, CT-based predictive model of aortic prothesis size were developed using univariable linear regression (Table 5).

\section{Discussion}

The major finding of this study is that CT-calculated aortic annulus diameter is more reliable than TTE preoperatively and hence could be used to develop a predictive model of prosthesis size, eventually preventing PPM.

Several preventive strategies can be considered when PPM following AVR is likely [3]. A newly developed generation of prosthesis, the stentless bioprosthesis, is a valve designed for supra-annular implantation [9]. The new era of transcatheter AVR (TAVR) also promised to lower the prevalence of PPM, with supporting data from Asian population $[10,11]$. Nevertheless, these valves might not be commercially available or too costly for patients in developing countries. Under these circumstances, aortic root enlargement (ARE) is commonly indicated to place a larger valve and has been performed for many years. However, not only does this practice add to operation time and complexity, but could also negatively affect morbidity and mortality in the field of minimally invasive surgical AVR, such as mini-thoracotomy and upper ministernotomy [12]. In addition, ARE is associated with several complications, such as mitral valve prolapse and aorto-left atrial fistula [13]. Therefore, recognizing the

Table 3 Prosthesis size according to different suture techniques and surgical approaches

\begin{tabular}{llc}
\hline Variables & Prosthesis size & P-value \\
\hline Suture technique & & 0.124 (t-test) \\
Intra-annular single suture $(n=73)$ & $21.1 \pm 1.7$ & \\
Supra-annular pledgeted suture $(n=41)$ & $20.8 \pm 1.8$ & 0.349 (One-way ANOVA) \\
Surgical approach & & $21.4 \pm 1.67$ \\
Full sternotomy & $21.4 \pm 1.96$ & $20.7 \pm 1.89$ \\
Upper ministernotomy & & \\
Second intercostal minithoracotomy & & \\
\hline
\end{tabular}


Table 4 Pearson correlation coefficients between imagingmeasured diameters and intraoperative prothesis size

\begin{tabular}{llll}
\hline Imaging modality & \multicolumn{3}{c}{ Calculated aortic annulus diameters } \\
\cline { 2 - 4 } & All patients & $\begin{array}{l}\text { Mechanical } \\
\text { valve }\end{array}$ & Tissue valve \\
\hline $\begin{array}{l}\text { TTE diameter (PLAX diam- } \\
\text { eter) }\end{array}$ & 0.59 & 0.65 & 0.49 \\
$\begin{array}{l}\text { CT scan } \\
\text { Mean diameter }\end{array}$ & 0.79 & 0.79 & 0.79 \\
$\begin{array}{l}\text { Perimeter-derived diam- } \\
\text { eter }\end{array}$ & 0.76 & 0.77 & 0.76 \\
Area-derived diameter & 0.75 & 0.73 & 0.76 \\
\hline
\end{tabular}

$C T$ computed tomography, PLAX parasternal long axis view, TTE transthoracic echocardiography need for ARE and adequately determining a patient's risk of PPM are crucial prior to AVR.

This study compared preoperative CT scan and TTE measurements of aortic annulus diameter to intraoperative annular sizing. Our results agree with previous literature, which indicated that CT-based calculations were better correlated with operative values. In particular, Kempert et al. demonstrated that utilizing the "effective" diameter on CT scan is preferable to TTE values in patients with oval-shaped annulus [14]. Likewise, Daskevish et al. found that the calculated annular measurements with $\mathrm{CT}$ are closer to operative sizing with a Hegar dilator [8]. While suggesting that imaging modalities (CT and TTE) could be fairly accurate in predicting the aortic annulus size, both studies shared similar limitations, i.e.

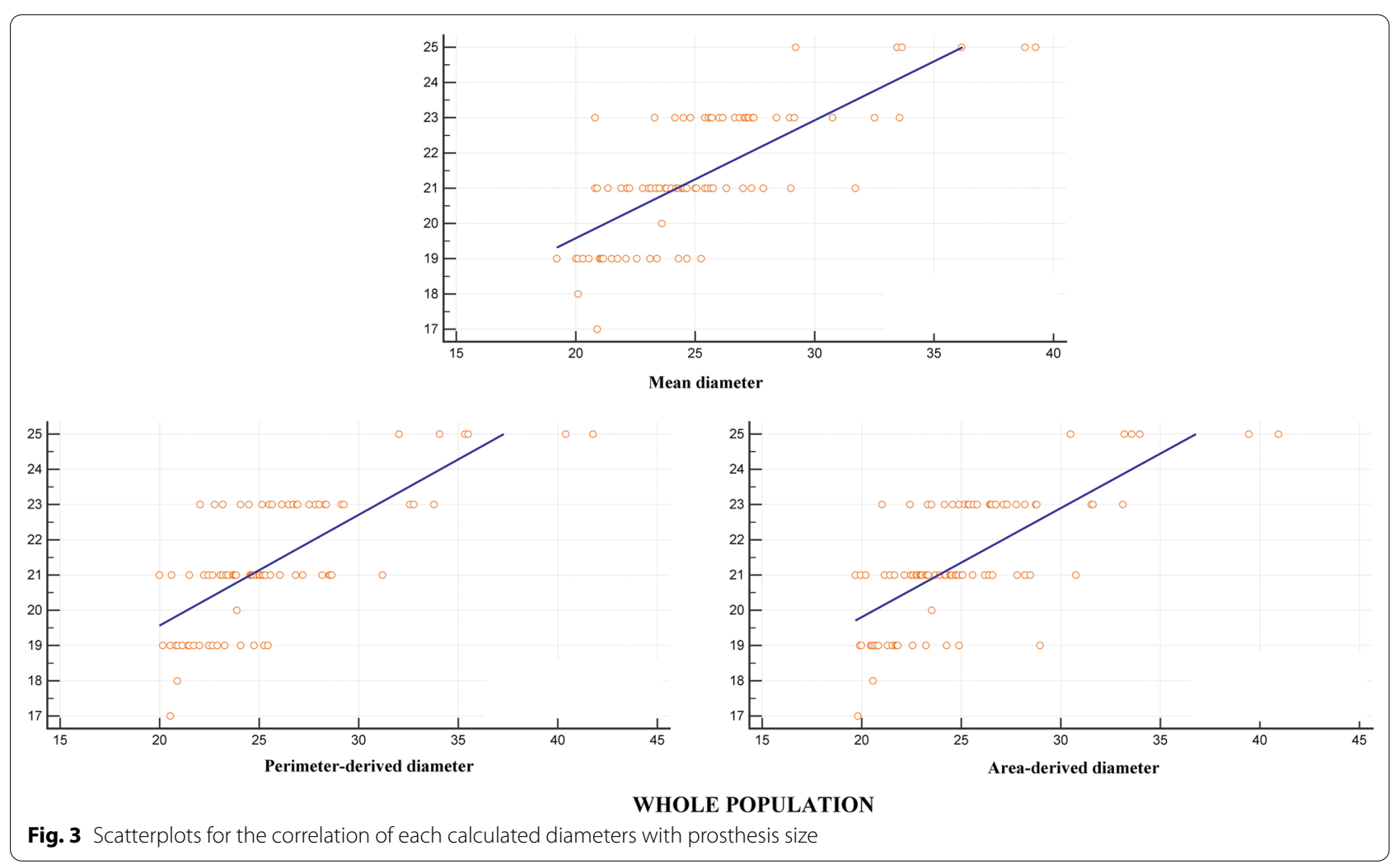

Table 5 CT scan-based prediction model of aortic prosthesis size

\begin{tabular}{llll}
\hline Calculated diameter & All patients & Mechanical valve group & Tissue valve group \\
\hline Mean diameter & $12.89+0.335 \times d$ & $11.104+0.378 \times d$ & $13.068+0.341 \times d$ \\
& $\left(R^{2}=0.6241\right)$ & $\left(R^{2}=0.6241\right)$ & $\left(R^{2}=0.6241\right)$ \\
Perimeter-derived diameter & $13.275+0.315 \times d$ & $11.213+0.371 \times d$ & $13.724+0.308 \times d$ \\
& $\left(R^{2}=0.5776\right)$ & $\left(R^{2}=0.5929\right)$ & $\left(R^{2}=0.5776\right)$ \\
Area-derived diameter & $13.626+0.309 \times d$ & $11.593+0.363 \times d$ & $13.910+0.310 \times d$ \\
& $\left(R^{2}=0.5625\right)$ & $\left(R^{2}=0.5329\right)$ & $\left(R^{2}=0.5776\right)$
\end{tabular}

$C T$ computed tomography, $d$ corresponding calculated diameter, $R^{2} R$-squared, coefficient of determination of the model 
small sample size (26-33 patients) and did not establish predictive models. A recent review by Pibarot et al. proposed an algorithm to predict and prevent PPM by using multidetector CT or 3D TEE but still did not provide an estimated prothesis size preoperatively [3]. This could lead to unplanned ARE during AVR and pose major challenges to inexperienced surgeons.

The superiority of CT scan over echocardiography can be explained as follows. TTE is echocardiographerdependent, and a single dimension on PLAX cannot represent the whole aortic annulus. On the other hand, CT scan provides three different diameters (mean, perimeter-derived and area-derived diameter) that are fairly comparable when calculating the prosthesis size preoperatively. In practice, however, echocardiography is noninvasive and presents as the only option when CT scan is contraindicated or unavailable. Hence, measurements predicted from TTE alone could still be considered while bearing in mind that they might not be as accurate as $\mathrm{CT}$ scan-based. Our study showed that CT-calculated algorithms for mechanical and tissue valve shared similar coefficients, thus proving CT-based predictor as applicable for both prothesis types. Overall, we recommend combining all three diameters on CT scan to minimize possible errors during measurements.

To our knowledge, this is the first study to propose a quantitative, imaging-based model to predict PPM prior to AVR. Knowing each patient's predictive prosthesis size, surgeons can anticipate and develop suitable strategies (eg using valves with larger EOAi, preparing for ARE or performing TAVR in lieu of surgical AVR) before incision. This would in turn help decrease morbidity caused by unintended procedures and lead to better patient outcome.

The main limitations of this study are its retrospective nature, small sample size and that few types of prostheses were used to establish the predictors. As different manufacturers produce protheses with similar size but largely inconsistent dimensions, the two most popular prostheses in our center were chosen to increase the model accuracy $\left(\mathrm{SJM}^{\mathrm{TM}}\right.$ Masters Series for mechanical valve and Carpentier-Edwards PERIMOUNT Magna Ease for bioprosthesis). As a result, the suggested algorithm might only apply to these two and further studies using a wider variety of prothesis types are needed.

\section{Conclusions}

Preoperative CT scan measurements is efficient in predicting the size of aortic prosthesis. If CT is contraindicated or unavailable, TTE is an alternative imaging method, though its dependence on echocardiographers and inability to represent the full aortic annulus limit its accuracy. Together, these two imaging modalities can be incorporated into a quantitative and straightforward algorithm to predict PPM preoperatively.

\section{Abbreviations}

AVR: Aortic valve replacement; ARE: Aortic root enlargement; PPM: Patientprosthesis mismatch; CPB: Cadiopulmonary bypass; TAVR: Transcatheter aortic valve replacement; ICU: Intensive care unit; CT: Computed tomography; TTE: Transthoracic echocardiography; TEE: Transeophageal echocardiography; PLAX: Parasternal long axis; LVOT: Left ventricular outflow tract; EOA: Effective orifice area.

\section{Acknowledgements}

Not applicable

\section{Authors' contributions}

Conceptualize: ATV, DHN. Design: ATV, TTTN. Carry out analyses: TN, TTTN, NTHN, NBL, THC. Intepret study results: ATV, TTTN, TN, NTHN. Draft manuscript: ATV, TN. Revise: DHN. Approve final manuscript: ATV, TN, TTTN, NTHN, NBL, THC, DHN. All authors read and approved the final manuscript.

Funding

The authors received no specific funding for this work.

\section{Availability of data and materials}

The datasets used and/or analysed during the current study are available from the corresponding author on reasonable request.

\section{Declarations}

Ethics approval and consent to participate

The research was approved by the ethical board of the University of Medicine and Pharmacy at Ho Chi Minh City, number 146/HDDD-DHYD, on February 22nd 2021.

\section{Consent for publication}

All authors of this paper have read and approved the final version submitted.

\section{Competing interests}

The authors declare that they have no competing interests.

\section{Author details}

${ }^{1}$ Department of Cardiovascular Surgery, University Medical Center, University of Medicine and Pharmacy at Ho Chi Minh City, 215 Hong Bang Street, District 5, Ho Chi Minh City, Vietnam. ${ }^{2}$ Department of Cardiovascular Surgery, Faculty of Medicine, University of Tsukuba, Tsukuba, Japan. ${ }^{3}$ Department of Thoracic and Cardiovascular Surgery, Faculty of Medicine, University of Medicine and Pharmacy at Ho Chi Minh City, Ho Chi Minh City, Vietnam. ${ }^{4}$ Department of Surgery, Nguyen Tri Phuong Hospital, Ho Chi Minh City, Vietnam.

Received: 31 May 2021 Accepted: 28 July 2021

Published online: 04 August 2021

\section{References}

1. Rahimtoola SH. The problem of valve prosthesis-patient mismatch. Circulation. 1978;58(1):20-4.

2. Bilkhu R, Jahangiri M, Otto CM. Patient-prosthesis mismatch following aortic valve replacement. Heart. 2019;105(Suppl 2):s28-33.

3. Pibarot P, Magne J, Leipsic J, et al. Imaging for predicting and assessing prosthesis-patient mismatch after aortic valve replacement. JACC Cardiovasc Imaging. 2019;12(1):149-62.

4. Khan MS, Bawany Fl, Dar MI, et al. Predictors of the size of prosthetic aortic valve and in-hospital mortality in aortic valve replacement. Glob J Health Sci. 2014;6(4):177-82.

5. Dayan V, Vignolo G, Soca G, et al. Predictors and outcomes of prosthesispatient mismatch after aortic valve replacement. JACC Cardiovasc Imaging. 2016;9(8):924-33. 
6. Pibarot P, Dumesnil JG. Hemodynamic and clinical impact of prosthesispatient mismatch in the aortic valve position and its prevention. J Am Coll Cardiol. 2000;36(4):1131-41.

7. Lancellotti P, Pibarot P, Chambers J, et al. Recommendations for the imaging assessment of prosthetic heart valves: a report from the European Association of Cardiovascular Imaging endorsed by the Chinese Society of Echocardiography, the Inter-American Society of Echocardiography, and the Brazilian Department of Cardiovascular Imaging. Eur Heart J Cardiovasc Imaging. 2016:17(6):589-90.

8. Dashkevich A, Blanke P, Siepe M, et al. Preoperative assessment of aortic annulus dimensions: comparison of noninvasive and intraoperative measurement. Ann Thorac Surg. 2011;91(3):709-14.

9. Morita S. Aortic valve replacement and prosthesis-patient mismatch in the era of trans-catheter aortic valve implantation. Gen Thorac Cardiovasc Surg. 2016;64(8):435-40.

10. Miyasaka M, Tada N, Taguri M, et al. Incidence, predictors, and clinical impact of prosthesis-patient mismatch following transcatheter aortic valve replacement in Asian patients: the OCEAN-TAVI Registry. JACC Cardiovasc Interv. 2018;11(8):771-80.
11. Takagi $H$, Umemoto T, Group A. Prosthesis-patient mismatch after transcatheter aortic valve implantation. Ann Thorac Surg. 2016;101 (3):872-80.

12. Yu W, Tam DY, Rocha RV, et al. Aortic root enlargement is safe and reduces the incidence of patient-prosthesis mismatch: a meta-analysis of early and late outcomes. Can J Cardiol. 2019;35(6):782-90.

13. Massias SA, Pittams A, Mohamed M, et al. Aortic root enlargement: when and how. J Card Surg. 2021;36(1):229-35.

14. Kempfert J, Van Linden A, Lehmkuhl L, et al. Aortic annulus sizing: echocardiographic versus computed tomography derived measurements in comparison with direct surgical sizing. Eur J Cardiothorac Surg. 2012;42(4):627-33.

\section{Publisher's Note}

Springer Nature remains neutral with regard to jurisdictional claims in published maps and institutional affiliations.
Ready to submit your research? Choose BMC and benefit from:

- fast, convenient online submission

- thorough peer review by experienced researchers in your field

- rapid publication on acceptance

- support for research data, including large and complex data types

- gold Open Access which fosters wider collaboration and increased citations

- maximum visibility for your research: over $100 \mathrm{M}$ website views per year

At BMC, research is always in progress.

Learn more biomedcentral.com/submissions 